\title{
5. NEW MEDIA ART: ALIGNING ARTISTIC CREATIVITY AND TECHNOLOGICAL MEDIA
}

\author{
Cătălin Soreanu ${ }^{205}$
}

\begin{abstract}
This article investigates the relationship between art and technology, pointing the constants of a process of cultural digestion which is mediated by the very sovereign technological environment - the Internet. Relying on the multiplicity and hybridization of the content formats, and also on the user involved interactivity as constructive vectorrelationships, new media art and the internet art are natural consequences of the artistic practices of creative appropriation of contemporary technological media. As the complexity of the relationship between art and the technological environment becomes richer than ever, we assist to the creation of a contemporary ultra-technological culture, structurally dependent on the media and responsible for relativizing the critical positioning of the art consumer. Defining the premises of the interaction with a technologically interfaced world of art, the user (reader) of the Internet as a medium of expression is - equally - a consumer, and a producer of information (content).
\end{abstract}

Key words: internet, medium of expression, new media art, technology

\section{Introduction}

In this article, we discuss the cutting-edge technologies that marked the second half of the twentieth century and the transition to the twenty-first century, linking video art (60s) and computer art (70s) with the emergence of performance, happening, and of the artistic installation, genres that allowed - in an expressive synchronicity unprecedented in the history of art - the alignment of artistic creativity with the technological potential of communication media. As the first commercial Web browser (Netscape Navigator, 1994) became accessible to the general public, it marked the transformation of the Internet from a network of academics and computer scientists, into a popular medium for personal communication, advertising, and trade. The Internet has soon become the favourite space for a lot of activities, imposing dramatic changes in industrial production and the computer economy, in various networks and markets. (Triebe and Reena 2009, 6). The potential of such an environment has meant an immeasurable communication opportunity for media magnates and an inexhaustible source of inspiration for many artists, curators and critics who have used the title of New Media Art for creations based on digital technology, the use of the Web or virtual reality environment.

\section{A terminological approach}

The "new media" terminology is relative and has technological (rather than cultural) connotations. Introduced in the 1990s, when it referred to various forms of publishing and distributing information on magnetic media (such as the CDROMs, or even the Web space), to differentiate them from "old media"

${ }^{205}$ Lecturer PhD., „George Enescu” National University of Arts from Iaşi, Romania, email: csoreanu@gmail.com 
represented by existing information dissemination technologies like the written press (specific to newspapers) or the audio-visual one (in radio and television ${ }^{206}$ ), new media defines the multitude of communication media based on digital technology, with its extensions and fields of application. Today, the sovereign technological tool - the computer, with all its forms and variations of computing laptop, tablet, desktop, smart-phone, graphics station, smart-watch - is a computing structure that mediates our daily interaction with immediate existence, in an extensive, totalitarian and implicit manner and, most of the time, it was at the centre of artistic practices as the main means of artistic expression to which the new media generation appeals.

In a chronological course of the production of artistic forms, from the dawn of cinema, the advent of television and video art, and with the advent of the computer, virtual realities and social media, each technological age has built cultural realities in which information, access, management, processing and storage become active components, prolific mechanisms of conceptualizing the work with technological environments, assiduously appropriated by artists.

The border between various arts and technologies is increasingly mobile, as the graphic arts, the sculpture, the installation, the photography, the performance, are all in contact with new technologies and feeding on them (German 2018). Typical names such as digital art, computer art, multimedia art or interactive art are relative, trying to point out - often unidirectional - various perspectives on approaching the same field of artistic action. Interchangeable, they can be easily framed in the umbrella-term of ,new media art”, which describes artistic projects made with the help of new technologies that address contemporary cultural, political or aesthetic realities, works of art constantly characterized by a certain level of conceptual sophistication, diversity and technological innovation and social relevance. A terminological dissociation is offered by separating the predominantly technological practices from the media ones (thus ,art and technology" versus ,art and communication"); more precisely, electronic art, robotic art and genomic art versus video art, transmission art and experimental film. The art of new media is at the intersection of these two orientations, in a continuous and fluid acceptance of the changes of communication technologies that are evolving at an accelerated pace.

\section{The connection with visual arts}

The artistic practices specific to new media are the natural result of the cultural, the technological, as well as of the artistic changes from the 20th century. New media art is a natural response to the information technology revolution and the digitization of culture specific to the last decades, just as the Dada movement was a reaction to the industrialization and mechanized reproduction of images and texts. With a predilection for experiment and chance, Dadaist strategies such as photomontage, collage, ready-made, action or performance, appeal to irony or absurdity as forms of socio-political criticism, are

\footnotetext{
206 Back in 1994, the American giant corporation Hearst, which owned numerous periodicals and television networks, created divisions dedicated to New Media. (Triebe and Reena 2009, 6)
} 
recurring as specific new media strategies and artistic practices. Examples are the works made by Shue Lea Cheang and Diane Ludin ${ }^{207}$ that recall the imagery of collages made by Raoul Hausmann or Fracis Picabia; also, the practice of Duchampian ready-made is constantly found in media constructions such as "WWWWArt Award" by Alexei Shulgin or "Prepared PlayStation" by RSG (2005) (EAI 2020); Hugo Ball's absurd poems approach is found in "Free Radio Linux" by r a d i o q u a 1 i a ${ }^{208}$; activist-political projects such as "Borderhack" from 2000-2005 by Fran Illich or "FloodNet" by Electronic Disturbance Theater reminiscent of predecessors such as George Grosz (1893-1959), John Heartfield (1891-1968) and other Berlin Dadaists (Scheeres 2008).

In the 60's of Pop Art movement, the EAT group (Experiments in Art and Technology) was founded, formed by Billy Klüver and Fred Waldhauer, collaborating (among others) with Andi Warhol, Robert Rauschenberg, Jasper Johs and John Cage, artists open to collaborative formulas between visual art, music, dance and other forms of culture, drawing the premises for the scientific approach to the interdisciplinary artistic phenomenon that laid the foundations of hacking-art, software-art and internet-art practices in research and development centres such as the MIT Media Lab in Cambridge, USA (The Daniel Langlois Foundation for Art, Science, and Technology 2003). Pop Art is another important precursor of new media art, as an echo of the consumer culture, specific to the '60s, with image and video mixes such as the "Trigger Happy" installation (1998) by Thompson \& Craighead, as the simulation of a space-shooters game where words can be removed from a sentence, thus alternating the meaning of the resulting phrase (Thomson and Craighead 1998), or the pixel-based reconstructions of the group of artists working behind the pseudonym eBoy (founded in 1997 by Kai Vermehr, Steffen Sauerteig and Svend Smital, based in Berlin and Vancouver), which evokes the comic book sequences of Roy Lichtenstein (1923-1997), works that but remain in the environment from which they come, in an organic assembly that respects the technological particularities media $^{209}$.

A visible notice is that the 2000s generation of artists tend to use the web browser in almost the same way in which, in the 60s, the video environment was approached by artists such as Bill Viola, Bruce Nauman or Joan Jonas ${ }^{210}$, by the appropriation and use of a technological tool that allows the creative exploration of the organic relationship between technology and culture, in all its forms (Guggenheim.org 2020). The predominantly conceptual dimension of new media

\footnotetext{
${ }^{207}$ Shu Lea Cheang is an artist who works with various artistic art and film formats, creating installation, performance, net art, public art or video and feature film. (https://tentacular.es/en/programa/shu-lea-cheang, accessed at 20.05.2020), and Diane Ludin is an UI poet, media artist and designer. (https://www.poetryproject.org/people/diane-ludin, accessed at 22.05.2020)

${ }^{208} \mathrm{http}: / / \mathrm{www}$. radioqualia.net/freeradiolinux (accessed at 20.05.2020)

${ }^{209}$ For example, the above-mentioned game included in the 1998 multimedia installation "Happy Trigger" can be played directly in the web browser, unlike the video consoles available at that time. (www.triggerhappy.org, accessed at 04.01.2021)

${ }^{210}$ This is a simultaneous issue with the introduction of the PortaPak (model of portable analogue video camera, released in 1967) (Bensinger 1981, 155). Prior to this period, we can note the experimental pioneering initiatives in the video art of the artist Nam June Paik.
} 
art is obvious from the perspective of its stake on discursive legitimation, on idea and concept, and not strictly on artistic objectivity. The new media manifestations are bordering the same direction of approach specific to the conceptual art of the 60 s, especially in the absence of the association of a formal aesthetic that supports the artistic results/artworks. The quasi-present resources that characterize the specific artistic practices new media are the virtual environment, the digital materialization of the artistic substance, and the temporal projection of the conceptualized results.

\section{New media as art}

With the intense industrialization of the art market, the contemporary art is characterized by an accentuated polarization of manifestations that oscillate between institutionally subsidized artistic production and independent echoes, movements that build a varied and fragmented synoptic picture, where the traditional artistic environments are reconsidered, and the vacuum of established artistic landmarks allows the experimental approach of other artistic media landmarks. In such a context, where modern communication media themselves become significant (Gheorghe 2010) and the entire production, dissemination and reception of artistic manifestations are conditioned by reporting / integration to the digital environment, the concept of new media art becomes quasi-present in museums and galleries where installations and videos, digital and interactive art become the dominant expression of an entire generation of artists (Soreanu, Artă și publicitate. Medii de expresie în publicitatea contemporană 2018). Museums, art fairs, biennials, galleries abound with multimedia projects, production moves online, digestion and artistic consumption become the prerogative of an audience connected to existing realities (both literally and figuratively).

The art of new media has a deep global character, given the close connection with the technological environment of the internet. The multitude of websites, email lists, social media platforms, streaming services facilitated by the huge physical network of the Internet have offered as many alternatives for channelling communities of creation, promotion or exhibition of specific works of art, forming an online art scene, a real and consistent alternative to the world of contemporary art, defined by digital culture. The internationalization of the new media art movement reflects the growth of the art world with the development of international art biennials, a result of cultural and economic globalization specific to recent decades, in turn a consequence of the development of communications networks - Internet, cloud technologies, GPS, mobile telephony, an echo of the metaphor of the global village predicted by Marshall McLuhan a few decades earlier (McLuhan 1964). The development was bilateral, generating demand for these technologies which, in turn, created opportunities for globalization, international connections, partnerships and exchanges of ideas, whose effects on society are reflected in new media art forms, as elements of analytical criticism of the impact that this media-centric culture has on contemporary art.

An essential role in the emergence of the new media artistic current was the concern for what was called, in the mid-90s, net-art (or internet-art), the structure and network of the Internet being - equally - the environment and the trigger that 
provided artists with limited means of production the opportunity to manifest in the public space (online). Requiring only a computer, internet access and technical skills to work with the digital environment, such an artistic practice capitalizes on the media context and the inexhaustible resource of information available on the Internet, amid the democratization of access to forms of technology (video and cameras, development PCs, mobile phones) and the internet (with the example of the former communist countries where the transition to capitalism was doubled by the privatization of the internet and the relative liberalization of access to information).

After the mid-90s, the progress in the development of computers and dedicated applications provided enough computing power to create web pages, manipulate images, 3D models, edit video and audio content by personal users, respectively by a generation of artists who grew up with personal computers and video games ${ }^{211}$ (just as the new millennium generation is completely familiar with touch screens and cloud technologies). At the time of the emergence of what we now call new media art, we can observe the essential conditions for the development of the global art scene, unprecedented progress in information technology and familiarization of new generations of artists with the world of computers and computing devices increasingly accessible (Triebe and Reena 2009). The consequence has been an intense activity of using the Internet to disseminate forms of media documentation of existing works of art or created in other environments (creation of presentation websites, online portfolios, databases), but especially of the use of the Internet as a distinct medium of artistic expression, the potential of which has been approached with a sense of creative fervour sustained by the interest of artists in exploring new technologies.

\section{Evaluating the artistic practices within new media art}

In new media art, the complexity of artistic practices in which frequent collaborations between several artists (either in ad-hoc groups or in long-term partnerships) give rise to large, complex projects that require a variety of technological skills and artistic to produce digital projects/objects (Manovich 2001, 14). Sometimes, they define themselves as collective groups of artists associated on ideological or practical criteria (which voluntarily distance themselves from the romantic image of the solitary artistic genius). Many new media artworks require audience participation to produce, validate, or even engage in building specific dimensions of the project. The very interface needed to browse or view the new media artwork can be an interactive tool (a web page, with menus and navigation tools) in which the visitor (or reader) plays an active role in building meaning (by, for example, controlling the development of a narrative, video or textual thread). The web project "My Boyfriend Came Back From the War" from 1996 is such an example of the artist Olia Lialina ${ }^{212}$, in which browsing a website involves preferential access to different frames of

\footnotetext{
211 The first Apple Macintosh personal computer was introduced in 1984. (Dernbach 2020)

212 The project can be accessed online, in a simulation that offers internet access through Netscape Navigator: https://sites.rhizome.org/anthology/lialina.html (accessed at 2020.05.23)
} 
image or text, with the visitor building his own narrative thread (Lialina 2020).

The practice of assuming-ownership is common in the art of new media, as working with resources made available online means sharing them with an audience that, in turn, can be an active part of the creative process. Social media platforms, sharing practices, building online content generated by the user, are artistically appropriated strategies that start from identifying, appropriating and reusing multimedia content. The distinction between reading and appropriation, between the provision and the availability of content is blurred. The abundance of online content, of source material, together with the ease of its capitalization (sharing, copying, reposting), have contributed to the finalization of creative strategies already settled in modern and post-modern artistic practice where ready-made, quotation, irony, appropriation, repositioning are ubiquitous artistic formulas (Soreanu, The Sacred In Contemporary Advertising 2016). An example is "After Sherrie Levine," a 2001 work in which the author Michael Mandiberg makes an absurd-appropriation online copy of Sherrie Levine's 1979 work, in turn replicas of Walker Evans' classic photographs on the "American depression" period. The resulted website ${ }^{213}$ provides instructions on how the images (obtained by scanning a printed album) can be printed and accompanied by a self-provided certificate of authenticity. The project is an invitation to be part of an explicit strategy of re-signification of images by creating objects with cultural value, but without economic value, using practices of appropriation and citation which are specific to postmodern art (Mandiberg 2020).

Assuming freedom to use and reuse online content lead to the creation of copyright policies to protect the rights of authors and - in the mirror - of opensource platforms, conceptual reflections of restrictions on access to use and reuse of information. The open-source-software model is, moreover, an echo of new media artistic practices where intellectual property has always been doubled by altruism and mutual recognition of authorial involvement, along with creative acceptance of the environment, its constraints and opportunities. As followers of open-source policies, new media artists tend to appropriate their online content, work collaboratively and share the results without constraints for the online community. Examples of such projects are "Super Mario Clouds" by Cory Archangel ${ }^{214}$, "Carnivore" developed by the RSG group (Radical Software Group) - a software tool programmed to monitor information on a network, data that can be interpreted later by the user" ${ }^{215}$, or "OPUS (Open Platform for Unlimited Signification!") by Raqs Media Collective, presented at the 2002 International Contemporary Art Exhibition "Documenta 11" in Kassel, Germany.

Not coincidentally, the new media artists reinterpreted works or projects from the art of the 60's, making digital mixes as Duchampian echoes of Pop Arttype recycling. MTAA, a group formed in 1996 by New York artists Michael

\footnotetext{
${ }^{213}$ The project consists of two similar websites, accessible online at URLs http://www.aftersherrielevine.com and http://www.afterwalkerevans.com (accessed at 2020.05.23)

${ }^{214}$ Website and files shared by the artist available on http://www.coryarcangel.com/things-i-made/2002-001super-mario-clouds (accessed at 23.05.2020) (Arcangel 2002)

${ }^{215}$ Source code and resources available online on the artist's website at http://r-s-g.org/carnivore/ (accessed at 23.05.2020)
} 
Sarff and Tim Whidden, created in 2001 (until 12/10/2002) "OnKawaraUpdate", a software replica of the aesthetics of the works of conceptual artist On Kawara (Sarff și Whidden 1996), and Wolfgang Staehle remakes Warhol's 1964 work "Empire" (an 8-hour film about Empire State Building) made with video streaming using a webcam, a project entitled "Empire 24/7", first exhibited in 1999 at ZKM, Karlsruhe ${ }^{216}$. Another relevant example is the group of artists Jennifer and Kevin McCoy who use database-specific textual algorithms to allow users to edit and reinterpret the video content of Stanley Kubrick's "2001: A Space Odyssey" in the "201: A Space Algorithm" project from 2001 217.

\section{Institutional recognition vs. independent movements}

The new media art movement can be approached from the perspective of its acceptance by the official contemporary art scene, respectively the world of museums and art galleries, or from the perspective of manifestations of independent initiatives, created by and for professionals in the field, outside these official artistic circuits. Despite the scepticism of the followers of the "old" artistic media, in the 90's, new media began to attract the attention of museums, galleries and art institutions. Attempts to approach technically conditioned art forms date back to the 1970s, when the Institute for Contemporary Art in London (ICA) organized "Cybernetic Serendipity", an exhibition based on artistic practices influenced by the specific technology of computer automation (Medien Kunst Netz 1968), and In New York, the Jewish Museum produced the exhibition "Software" in which computer programming language was treated as a metaphor for conceptual art (Glueck 1970), (Monoskop.org 1970). A year later, the Los Angeles County Museum of Art (LACMA) exhibited the artistic results of an initiative that brought together contemporary artists such as Robert Irvin, Robert Rauschenberg and Richard Serra, in collaboration with various technology corporations.

The 1990s is what is accepted as the beginning of the new media period as an artistic movement, with various events in the American artistic space. At the SFMoMA (San Francisco Museum of Modern Art), "Bay Area Media" takes place in 1990, an exhibition curated by Robert Riley that includes various works of computer-generated art, such as the interactive installation "Deep Contact" by artist Lynn Hershmann or the video project Jim Campbell's "Hallucination" (Triebe and Reena 2009, 21). Three years later, curator John Ippolito of the Guggenheim Museum in New York organized the exhibition "Virtual Technology: An Emerging Medium" which introduced artistic approaches to virtual reality (early digital technological environment in 1993) (Rush 2006).

The following years abounded with forms of introduction and recognition of new media works that began to be purchased by galleries and museums as stand-alone pieces, such as Douglas Davis's 1994 "The World's First

\footnotetext{
${ }^{216}$ Work accessible on the website of the artist Wolfgang Staehle (http://www.wolfgangstaehle.info (accessed at 23.05.2020)

217 The "201: A Space Algorithm" project is available on the McCoy artists' website https://www.mccoyspace.com/project/48/ (accessed at 23.05.2020)
} 
Collaborative Sentence," purchased by the Whitney Museum of American Art, a collaborative work where visitors can intervene by adding words to an existing sentence in the digital environment (Whitney Museum of American Art 1994) ${ }^{218}$. In 1995, the Dia Center for the Arts Foundation in New York launched a project called "Artists' Web Projects" that addressed both established artists such as Cheryl Donegan, Francys Alys, and new media artists James Buckhouse or Kristin Lucas, offering them the possibility to realize net projects.art ${ }^{219}$. Another example is the Walker Art Center in Minneapolis, which is proposing an ambitious online project for commissioning new media works of art called "Gallery 9"220, coordinated by curator Steve Dietz (Walker Art Center 2020). And in 1997, the International Art Biennale "Documenta X" held in Kassel, includes a special section for Net Art, in recognition of the concerns of the entire generation of artists working in this environment, being the starting point for the world of contemporary art for acceptance, development, hosting, commissioning or recognition of new media art as an artistic movement (Documenta 1997).

More and more art institutions supported new media projects by the late 1990s, including the Cartier Foundation in Paris, the New Museum of Contemporary Art in New York, or the Institute of Contemporary Arts (ICA) in London, with prominent figures in the new media artists who become art curators at institutions such as SFMoMA (Benjamin Weil, co-founder of the Net.art website) or the Whitney Museum of American Art in New York (Cristiane Paul, founder of the journal "Intelligent Agent", in 2000). In the late 2000s, the Biennial of the Whitney Museum of American Art in New York (considered a barometer of guidelines in contemporary American art) included 9 works of net.art, such as "Ouija 2000" by Ken Goldberg or "Grammatron" from 1997 by Mark Amerika (Amerika 1998) 221 , defined by the author as a "narrative medium public domain" that sums up thousands of elements of textual, audio, animation and video content, programmatically managed by digital code sequences, made available to the public online (Whitney Museum of American Art 2000). A year later, Whitney dedicated a large art exhibition that included various forms of digital image processing, from new media art to extensions in painting and sculpture, while SFMoMA presents a similar exhibition entitled "010101: Art in Technological Times" (SFMoMA - San Francisco Museum of Modern Art 2001).

In addition to artists who have obtained official recognition and acceptance of their work by official contemporary art institutions, namely museums, galleries, art foundations, etc., there is a consistent group of exponents of the

\footnotetext{
${ }^{218}$ Douglas Davis's 1994 project "The World's First Collaborative Sentence" is still active online on the Whitney Museum of American Art website and may contribute to the continuation of that sentence. https://artport.whitney.org/collection/DouglasDavis/live/writesentence.html\#contribute (accessed 25.07.2020)

219 The institution's website is https://www.diaart.org (accessed 25.05.2020)

${ }^{220}$ The online exhibition space "Gallery 9" is hosted by the Walker Art Center (http://gallery9.walkerart.org, accessed 20.10.2020)

221 The GRAMMATRON project has been exhibited at Ars Electronica, The International Symposium for Electronic Art (ISEA), SIGGRAPH 98, The Telstra Adelaide Arts Festival (South Australia), Virtual Worlds 98 (Paris) and the International Biennial of Film and Architecture (Graz). http://www.grammatron.com (accessed 2020.05.19)
} 
movement who reject official channels of artistic validation, often activating within communities and institutions of art and media technology, in a universe close to the forms of language approached, manifesting themselves in events dedicated to art and technology such as the festival "Ars Electronica" in Linz, Austria (first organized in 1979) (Ars Electronica 2019) or the "Inter-Society for the Electronic Arts" (ISEA) symposium organized in $1988^{222}$ (previously named "Inter-Society for the Electronic Arts", founded in Holland in 1990). In 1997, ZKM - Zentrum für Kunst und Medien, a renowned research centre and museum in Karlsruhe, Germany (ZKM 2020) and The InterCommunicaton Center in Tokyo (ICC 1990), appeared as a new media art museum founded by the Japanese giant NTT, an initiative which joins other art research centres previously created in Japan by Canon and Shiseido (Triebe and Reena 2009).

However, a multitude of artists remain in the independent space and choose to express themselves through personal websites or other private institutions (various unrelated groups and institutional communities), through social platforms or email lists, all these in the non-conformist and anti-systemic spirit specific to the first new media art manifestations of the 90s. Various online communities in New York, such as "artnetweb" (founded in 1993 in New York by Remo Campopiano and Robbin Murphy as a collaborative platform dedicated to exploring new technologies), "Rhizome.org" (Tribe 1996) or "The Thing" (Staehle 1991), have played a key role in documenting, supporting and publishing new media works of art, followed by the emergence of physical centres such as "Eyebeam Atelier" and "Location One" in New York ${ }^{223}$ or "Internationale Stadt" and "Micro" in Berlin, "C3 - Center for Culture \& Communication Foundation" in Budapest ${ }^{224}$ or "[plug.in]" in Basel (plug.in 2001). One reason for these options is scepticism about the visible commercialization of the art scene and the art market, also explained by its critical stance on capitalism, since many artists come from Eastern Europe since the post-Cold War period.

\section{Conclusions}

With the Internet as an over-offering environment that tends to cover all the needs of the workflow and communication, from conception to realization, from promotion to online archiving and hosting of information, the social and professional interaction of today's activities is moving online. Cloud technology, initially seen as an online file sharing solution, has become a tool that encompasses active information processing applications, social platforms, promotion tools, commercial solutions, etc. Given the recent changes of pandemic months, we have all contemplating at the ability of the Internet to fully take over activities such as advertising image production, book publishing, order management, online exams and courses, application licensing, CV presentation, etc.

\footnotetext{
${ }^{222}$ ISEA International (http://www.isea-web.org/about, accessed 20.12.2020)

${ }^{223}$ Both centres were established in 1998 in New York (https://www.eyebeam.org/ and https://www.location1.org, accessed 4.01.2021)

${ }^{224} \mathrm{C} 3$ was established in 1996 as a result of a collaboration between Soros Foundation Hungary, Silicon Graphics Hungary and MATÁV (Telecom) (http://www.c3.hu/ accessed 4.01.2021)
} 
In the world of art, it is not surprising that we are witnessing sustained efforts to compensate by the online presence of those activities that can no longer be performed in physical, real life. The exhibitions are moving online, on web pages that only now are discovering their true utility, being seen until recently as additional, almost useless extensions of real events. The event openings are not replaced by video conferences. Participations in these events are made from the sofa in the living room, mimetically distributed by like and accept. The interaction takes place through audio or video conferences that tend to overwrite the (already traditional) form of dialogue through text messages, chat or email. Artistic projects are sent, displayed and confirmed online, diplomas are distributed virtually on the internet, opening speeches and openings are also consumed online. A synoptic look at the Internet will reveal the special importance of this technological communication environment on the way we live, completely changing the existential and artistic paradigm of contemporaneity, in a paradox of self-isolation that becomes, on the one hand, extremely productive for online artistic practices, and on the other hand, catalyse technologically disseminated creative energies into forms that have the ability to constantly change and creatively challenge the specifics of contemporary art.

\section{Publications}

\section{References}

1. Bensinger, Charles. The Video Guide. Santa Barbara, California: Video-Info Publications, 1981

2. German, Lavinia. "The relation between "seeing" and "being seen": a diachronic perspective on photographic view." Comunicarea interpersonală. Arta și educația ca mijloace de comunicare. Iași: Ars Longa, 2018. 187-193

3. Gheorghe, Cătălin. Condiția Critică. Iași: Institutul European, 2010

4. Manovich, Lev. The Language of New Media. Massachusets: The MIT Press, 2001

5. McLuhan, Marshall. Understanding Media. UK: Routledge, 1964

6. Soreanu, Catalin. Artă și publicitate. Medii de expresie în publicitatea contemporană. Iași: Artes, 2018

7. Soreanu, Catalin. "The Sacred In Contemporary Advertising." Edited by CodrinaLaura Ioniță, Puiu Ioniţă and Brînduşa Grigoriu. ANASTASIS - Research in Medieval Culture and Art (Artes) 3, no. 1 (2016): 149-158

8. Triebe, Mark, and Jana Reena. New Media Art. Cologne: Taschen, 2009

\section{Web resources}

1. Amerika, Mark. "about grammatron 1.0." Grammatron. 1998. https://www.grammatron.com/about.html (accessed 05 08, 2020)

2. Arcangel, Cory. Super Mario Clouds. 2002. http://coryarcangel.com/things-imade/2002-001-super-mario-clouds (accessed 05 23, 2020)

3. Ars Electronica. ARS on the WIRE. 05092019. https://ars.electronica.art/outofthebox/en/ars-on-the-wire/ (accessed 05 21, 2020)

4. Dernbach, Christoph. "The History of the Apple Macintosh." Mac History. 2020. https://www.mac-history.net/top/2020-02-10/the-history-of-the-apple-macintosh (accessed 05 21, 2020)

5. Documenta. Documenta $\quad X$. https://www.documenta.de/en/retrospective/documenta_X\# (accessed 05 25, 2020) 
6. EAI. "The EAI Collection: Artist Index." Electronic Arts Intermix. 2020. http://www.eai.org/ (accessed 05 16, 2020)

7. Glueck, Grace. “Jewish Museum's 'Software' Confusing." New York Times. 26 Sept 1970. https://www.nytimes.com/1970/09/26/archives/jewish-museums-softwareconfusing.html (accessed 05 18, 2002)

8. Guggenheim.org. "Bruce Nauman." Guggenheim.org. 2020. https://guggenheim.org/artwork/artist/bruce-nauman (accessed 12 20, 2020)

9. ICC. NTT InterCommunication Center. 1990. https://www.ntticc.or.jp/en (accessed $0521,2020)$

10. Lialina, Olia. Olia Lialina. 2020. http://art.teleportacia.org/ (accessed 05 23, 2020)

11. Mandiberg, Michael. mandiberg.com. 2020. http://www.mandiberg.com/ (accessed $0522,2020)$

12. Medien Kunst Netz. Cybernetic $\quad$ Serendipity. 1968. http://medienkunstnetz.de/exhibitions/serendipity/ (accessed 05 18, 2020)

13. Monoskop.org. Software - Information Technology: Its New Meaning for Art. 1970. https://monoskop.org/Software_(exhibition) (accessed 05 21, 2020)

14. plug.in. [plug.in]. 2001. https://monoskop.org/Plug.in (accessed 05 23, 2020)

15. Rush, Michael. "Virtual reality art: Beyond technology." The New York Times. 06 012006.2 https://www.nytimes.com/2006/01/06/arts/virtual-reality-art-beyondtechnology.html (accessed 05 25, 2020)

16. Sarff, Michael, and Tim Whidden. MTAA. 1996. http://mtaa.net (accessed 0519 , 2020)

17. Scheeres, Julia. "Borderhack: Barbed and Unwired." Wired.com. 23012008. https://www.wired.com/2001/08/borderhack-barbed-and-unwired/ (accessed 0523 , 2020)

18. SFMoMA - San Francisco Museum of Modern Art. 010101: Art in Technological Times. 2001. https://www.sfmoma.org/exhibition/010101/ (accessed 05 19, 2020).

19. Staehle, Wolfgang. THE THING. 1991. https://the.thing.net/home.html (accessed 05 23, 2020)

20. The Daniel Langlois Foundation for Art, Science, and Technology. E.A.T. - The Story of Experiments in Art and Technology. 2003. https://www.fondationlanglois.org/html/e/page.php?NumPage=236 (accessed 05 20, 2020)

21. Thomson, Jon , and Alison Craighead. "Triggerhappy." THOMSON \& CRAIGHEAD. 1998. http://www.thomson-craighead.net/thap.html (accessed 05 23, 2020)

22. Tribe, Mark. “Community.” Rhizome. 1996. Rhizome.org (accessed 05 20, 2020)

23. Walker Art Center. Walker Art Center. 2020. http://www2.walkerart.org (accessed $0105,2021)$

24. Whitney Museum of American Art. "Douglas Davis: The World's First Collaborative Sentence - Launched 1994, Restored 2013." Whitney Museum of American Art. 1994. https://whitney.org/artport/douglas-davis (accessed 05 12, 2020)

25. - Whitney Biennial 2000. 2000. https://whitney.org/exhibitions/biennial-2000 (accessed 05 23, 2020)

26. ZKM. "Archives." ZKM - Zentrum für Kunst und Medien Karlsruhe. 2020. https://zkm.de/en/collection-archives/archives (accessed 0105,2021 ) 